\title{
Partner Relationships and Sexual Desires: Has COVID-19 Impacted?
}

\author{
Jitendra K. Singh ${ }^{1,2^{*}}$, Dilaram Acharya ${ }^{3,4}$
}

\begin{abstract}
${ }^{1}$ Department of Medical Education and Research, Janaki Medical College, Tribhuvan University, Nepal, ${ }^{2}$ Centre for Clinical Research and Community Health (CC-REACH), MedSpirit Alliance, Kathamndu, Nepal. ${ }^{3}$ School of Public Health, University of Montreal, Montreal, Canada; ${ }^{4}$ Medical Affairs and Innovation, Héma-Québec, Montreal, Quebec, Canada
\end{abstract}

In addition to the respiratory illness, COVID-19 has remained an important ailment that impacting psychological being and distorted partner relationships, and hence has influenced sexual desires [1]. The COVID-19 outbreak has led almost all countries to implement public health measures such as working from home, as the major tool to reduced social contact [2]. Therefore, intimate relations have been uniquely influenced to a growing number of couples staying indoors for a longer period of time $[3,4]$. Partner relationship became crucial during the pandemic as one's partner may be the only person available for support, love, passion, and closeness. A supportive partner is important not only for survival, but also for thriving through the pandemic. Similarly, sexual desire is an important part of general well-being and has relevant consequences on people's daily lives [5]. The problem of forced prolonged cohabitation has an impact on both the partner sexuality and on autoerotic sexuality, a significant aspect of self-regulation and sexual wellbeing. However, it is not clear whether sexual behaviors among married couples have changed during the lockdown [6], for example, In Italy, government's decision of sudden lockdown in March 2020 forced couples to be separated, while others need to live together in the same home. The other study performed in different countries in the world reported that a decline in sexual quality along with a severe reduction in the frequency of intercourse during lockdown compared to the previous year. Among many other activities related to sexual activity as influenced by COVID-19 who were living with partner were: new sexual positions, BDSM, and acted out some sexual fantasies, while others tried to have new activities such as sexting who did not live with their partners [7]. Interestingly, a dramatic decrease in physical contact between couples in USA, and a greater majority $(60 \%)$ participants did not engage in sexual activity in UK as a result of fear of being infected with COVID-19 [5,8,9]. There are some of the significantly important factors associated with the sexual intensity are love, passion and intimacy, level of emotions and sexual desire while it might be loss of interest in sex and sexual activities is completely normal, considering libido levels which may change over time [1].

Although Chronic illness, stress, troubled relationship, alcohol and drug abuse, as well as aging may be some of the primary reasons behind low sex drive, it is possible to speculate that COVID-19 outbreak psychological outcomes are affecting the population's sexual desire. Despite having greater efforts to acknowledge the stress and anxiety of people who experienced during this pandemic of the deadly virus, there is scarce of evidence about the factors that influence the partner relationship and sexual desire during COVID19 pandemic. A recent Chinese study reported that out of the 459 participants, one in four people experienced a decrease in sexual desire amidst COVID-19 pandemic [10]. The fear of COVID-19 infection and prolonged lockdown have generated higher levels of anxiety in participants, leading to worsening of their relationship satisfaction, because when our body is under stress and anxiety, it releases hormones called cortisols and epinephrine, which in excess amounts found to be associated with lower sex drives. Additionally, lockdown imposed due to COVID-19 pandemic, has forced couples to be in 
social isolation. The anxiety connected to these specific aspects, as well as the uncertainty for future, negatively affected couple's relationship, since the partners were most probable and the only persons to confront and to lean on. Future studies should assess the outcomes of persistent somatic symptoms due to the COVID-19 lockdown on sexuality, after the emergency period.

Although there are no reports of mechanism of action for a direct link between the coronavirus disease and sex drive, experts have opined that the global pandemic may have affected us in a way that might lead to lower sex drive in both men and women. Both the small-scale studies and Centre for Disease Control and Prevention (CDC) have stated that the current pandemic might cause stress and anxiety in people. It is thus, there is possibility of having decreased libido in men and women because of COVID-19 crisis $[1,2]$. Studies have indicated that even if participants seem to show higher levels of resilience, the negative aspects of lockdown, such as anxiety, lack of privacy, fear of health conditions and psychosomatic symptoms, can affect the quality of sexual life. Since COVID-19 still be unpredictable, there is need for an adoption of some of specific measures such as to maintain positive mind set-ups and always stay healthy, eating healthy diet, exercising, avoiding alcohol or cigarette smoking and communicating with partners and others could be beneficial and meaningful for an improved partner relationship, sexual and quality of life.

\section{REFERENCES}

1. Times of India, Coronavirus: Has COVID-19 impacted your sex drive?

[https://timesofindia.indiatimes.co $\mathrm{m} /$ life-style/health-fitness/healthnews/coronavirus-has-covid-19impacted-your-sex-drive-hereshow-you-can-findout/photostory/86259143.cms]

2. Czeisler ME, Lane RI, Petrosky E et al. CDC. MMWR Morb Mortal Wkly Rep 2020;69.

https://www.cdc.gov/mmwr/volu mes/69/wr/pdfs/mm6932a1-H.pdf

3. Vowels LM, Carnelley KB, Francois-Walcott RR: Partner support and goal outcomes during COVID-19: A mixed methods study. European Journal of Social Psychology.

4. Carlson DL, Petts R, Pepin JR: US couples' divisions of housework and childcare during COVID-19 pandemic. SocAirXiv. 2020;6.

5. Ford, J. V., Corona Vargas, E., Finotelli, I., Fortenberry, J. D., Kismödi, E., Philpott, A., et al. Why pleasure matters: its global relevance for sexual health. sexual rights and wellbeing. Int. J. Sex. Health. 2019;31:217-30.

6. Arafat, S. Y., Mohamed, A. A., Kar, S. K., Sharma, P., and Kabir, R. Does COVID-19 pandemic affect sexual behaviour? A crosssectional, cross-national online survey. Psychiatry

Res. 2020;289:113050.

7. Lehmiller, J. J., Garcia, J. R., Gesselman, A. N., and Mark, K. P. Less sex, but more sexual diversity: changes in sexual behavior during the COVID-19 coronavirus pandemic. Leisure Sci. 2020;1-10.
8. Hensel, D. J., Rosenberg, M. Luetke, M., Fu, T., and Herbenick, D. Changes in solo and partnered sexual behaviors during the COVID-19 pandemic: findings from a US probability survey. medRxiv. 2020.

9. Panzeri M, Ferrucci R, Cozza A and Fontanesi L (2020) Changes in Sexuality and Quality of Couple Relationship During the COVID19 Lockdown. Front. Psychol. 11:565823. doi: 10.3389/fpsyg.2020.565823

10. $\mathrm{Li} \mathrm{W}$, $\mathrm{Li} \mathrm{G}$, Xin $\mathrm{C}$, et al. Challenges in the Practice of Sexual Medicine in the Time of COVID-19 in China. J Sex Med 2020;17:1225-1228.

\section{*Correspondence:}

Dr. Jitendra K. Singh

Centre for Clinical Research and Community Health (CC-

REACH), MedSpirit Alliance, Kathamndu, Nepal.

E-mail: jsingdj@gmail.com

ORCID: 0000-0002-1387-4642
Citation:

Singh JK. Acharya D. Partner Relationships and Sexual Desires: Has COVID-19 Impacted? MedS. J. Med. Sci. 2021;1(1):I-II 